\title{
A PERCEPÇÃO DE CLIENTES DE UM PROGRAMA DE RELACIONAMENTO NO VAREJO SUPERMERCADISTA
}

\section{RELATIONSHIP BETWEEN ORGANIZATIONAL CLIMATE TO SUPPORT INNOVATION AND QUALITY OF ACADEMIC LIFE}

\author{
Vívian Larissa Alves Araújo Arraes \\ Universidade Federal do Ceará - Fortaleza - CE \\ vivianlarissa@hotmail.com
}

\section{Francisco Juanito Costa da Silva}

Universidade Federal do Ceará - Fortaleza - CE francisco.juanito@gmail.com

\section{Érico Veras Marques}

Universidade Federal do Ceará - Fortaleza - CE ericovmarques@gmail.com

\section{Jocildo Figueiredo Correia Neto}

Universidade Federal do Ceará - Fortaleza - CE jocildo@ufc.br

\section{Resumo}

Administrar adequadamente o relacionamento com o cliente permite à empresa alcançar um diferencial perante a concorrência e gerar vantagem competitiva. Estas estratégias são gerenciadas pelo marketing de relacionamento, por meio da visão holística de CRM (Customer Relationship Management) ou gestão de relacionamento com o cliente. Para tal, é necessário conhecer melhor o cliente, aproximando-se dele e desenvolvendo ações que agreguem valor para ele e estimulem sua lealdade. Perante tal conjuntura, esta pesquisa objetiva identificar as variáveis mais significativas para a gestão de relacionamento com o cliente na percepção dos consumidores de uma rede de supermercados, de forma a analisar aquelas que são mais importantes para os clientes participantes do programa de relacionamento da empresa. Aplicou-se o estudo a 121 clientes cadastrados no programa de fidelidade de uma rede de supermercados presente em Fortaleza-CE. A pesquisa é classificada como estudo de caso, optando por uma abordagem quantitativa, com análise de dados feita por meio de análise fatorial, complementada por árvore de classificação. Dentre os principais achados, confirmou-se a importância de fatores citados pela literatura como ações essencias às estratégias de relacionamento, dentre elas, atendimento, personalização e qualidade. Além disso, destacou-se a importância da comunicação por meio de redes sociais e outras tecnologias que proporcionem contato direto com o cliente, desenvolvendo canais de aproximação que impulsionem 0 sucesso das ações de CRM.

Palavras-chaves: Marketing de Relacionamento; Gestão de Relacionamento com o Cliente (CRM); Setor Supermercadista; Percepção do Consumidor. 


\title{
A PERCEPÇÃO DE CLIENTES DE UM PROGRAMA DE RELACIONAMENTO NO VAREJO SUPERMERCADISTA
}

\begin{abstract}
Managing the relationship with the client allows the company to develop strategies that will ensure a differential in the face of competition and competitive advantage. These strategies are managed by relationship marketing, through the holistic view of CRM (Customer Relationship Management). To do this, it is necessary to work on actions that add value as to quality, service, communication and several other important factors for the client. These strategies make it possible to knowing better the client, to approach him in a good way and to develop actions that stimulate his loyalty, improving the brand image. Given this situation, this research aims to identify the most significant variables for the management of customer relationship in the perception of a supermarket chain consumers, in order to analyze the most important variables which can generate value for clients participating in the company's relationship program. For this, the study was applied to 121 clients enrolled in the relationship program of a supermarket chain located in Fortaleza-CE. The research is classified as a case study using a quantitative approach, with data analysis done by means of factor analysis, complemented by classification tree. Among the main findings, it is confirmed the importance of factors cited by the literature as essential actions to the relationship strategies, among them, care, personalization and quality. In addition, it was highlighted the importance of using communication through social networks and other technologies that provide direct contact with the client, developing channels of approach that drive the success of CRM actions.
\end{abstract}

Keywords: Relationship Marketing; Customer Relationship Management (CRM); Supermarket industry; Consumer Perception.

\section{Introdução}

O dinamismo e a complexidade no atual contexto competitivo das organizações, frutos do processo de globalização, caracterizam alguns dos fatores que levaram as empresas do mundo inteiro a voltar-se não somente para questões ligadas à produtividade do processo produtivo, mas para o aperfeiçoamento de seus negócios, com eficiência das operações e melhor relacionamento com fornecedores e clientes (RODRIGUES, 2014). A meta principal torna-se manter o cliente por meio de confiança, credibilidade e segurança transmitidas pela organização, construindo relacionamentos duradouros que contribuam para 0 aumento do desempenho para resultados sustentáveis (SANTOS et al., 2007).

Isso se faz ainda mais necessário no ramo varejista de supermercados, pois é um segmento altamente competitivo e de difícil diferenciação, já que a maioria de seus produtos caracteriza-se por commodity. 0 varejo está caminhando na direção de novos modelos; seja pela sustentabilidade, novas tecnologias ou experiências de compra, o varejo está mudando para acompanhar a transformação do comportamento do consumidor. Segundo Silveira e Lepsch (1997), tradicionalmente, o setor supermercadista é definido como um varejo generalista que revende para o consumidor final ampla variedade de produtos, dispostos de forma departamentalizada, no sistema de autosserviço. Esse sistema é caracterizado pela substituição da venda assistida, pois 0 atendimento é realizado através da seleção, por conta própria, dos produtos, os quais se encontram em gôndolas.

A importância do estudo deste setor pode ser justificada em dados econômicos. O setor supermercadista é responsável pela comercialização de $87,3 \%$ de todo alimento e produto de limpeza e higiene pessoal do Brasil e, somente em 2017, faturou $\mathrm{R} \$ 353,2$ bilhões, com crescimento nominal de 4,3\% em relação ao ano anterior. Assim, o setor representa 5,4\% do PIB do país (SBVC, 2018). Os supermercados brasileiros somam 89 mil lojas, com mais de 1,8 milhão de funcionários diretos e 5,4 milhões indiretos (ABRAS, 2017). Neste contexto, percebe-se que obter vantagem competitiva neste segmento de mercado por meio do bom relacionamento com clientes é essencial. Perante essa realidade, o setor supermercadista percebeu a necessidade de empregar o marketing de relacionamento de forma a desenvolver o gerenciamento do 


\section{Vívian Larissa Alves Araújo Arraes, Francisco Juanito Costa da Silva, Érico Veras Marques, Jocildo Figueiredo Correia Neto}

relacionamento com o cliente ou CRM (Customer Relationship Management) (CERIBELI; CERIBELI; MERLO, 2010).

De acordo com Gordon (2002), pode-se afirmar que as empresas que liderarão as cadeias de fornecimento serão aquelas capazes de assimilar conhecimento sobre o consumidor e o mercado, disseminar este conhecimento aos outros membros da cadeia e promover iniciativas que alinhem os objetivos da cadeia. Para isso, o foco principal das estratégias das empresas deve estar nos clientes. Gerson (1999) alerta que mais de $60 \%$ dos negócios das empresas vêm de clientes antigos, e que custa cinco vezes mais conquistar um novo cliente do que manter um existente. No entanto, Demo e Ponte (2008) ressaltam que a literatura já demonstra que o novo cliente custa dez vezes mais. Segundo Gerson (1999), um cliente insatisfeito pode contaminar cerca de dez pessoas, dentre as quais $13 \%$ relatam a insatisfação para mais vinte pessoas, pelo menos. Tais números remontam ao final do século passado. Assim, imaginar tal contingente em um ambiente de mercado no qual as redes sociais têm ativa participação no cotidiano dos clientes é algo que torna perceptível a dimensão de uma propaganda "boca-a-boca" negativa. McKenna (1997) ressalta que, para sobreviver no mercado competitivo, as empresas precisam traçar estratégias que sobrevivam às mudanças turbulentas do cenário, em constante evolução, principalmente pelos avanços da tecnologia da informação e comunicação (TIC).

Diante de tal conjuntura, surge o questionamento que incita esta pesquisa: que ações estratégicas ligadas à gestão de relacionamento com o cliente são mais relevantes e agregam mais valor frente aos clientes em um supermercado? Assim, o objetivo desta pesquisa é identificar as variáveis mais significativas para a gestão de relacionamento com o cliente na percepção dos consumidores de uma rede de supermercados. Para alcançar este intento, busca-se ainda nesta pesquisa: identificar ações estratégicas de marketing de relacionamento executadas pelo supermercado com o cliente; analisar a percepção dos clientes sobre tais ações; e identificar quais dessas estratégias mais se destacam para agregar valor ao gerenciamento deste relacionamento com o cliente, podendo desenvolver diferencial competitivo para a empresa frente à concorrência.

As seções a seguir discutem acerca dos conceitos de marketing de relacionamento. Em seguida, descrevese a metodologia utilizada na realização desta pesquisa. Posteriormente, o programa de relacionamento da empresa abordada é apresentado e os dados coletados são analisados. Por fim, são apresentadas as conclusões do estudo.

\section{Marketing de relacionamento e suas implicações}

A terminologia marketing de relacionamento foi introduzida na literatura por Berry (1983), que o definiu como atração, manutenção e aperfeiçoamento do relacionamento com o cliente. Mas foi na década de 90 que 0 marketing de relacionamento ganhou importância no cenário das discussões acadêmicas e empresariais (DEMO, 2015). Faria et al. (2014) afirmam, a respeito da produção acadêmica internacional sobre marketing de relacionamento, que ela cresceu substancialmente a partir da década de 1990, acompanhando 0 interesse crescente do ambiente empresarial. Quanto à produção nacional sobre o tema, durante a década 1990, houve pouca publicação de estudos a este respeito, mas, a partir da virada do milênio, houve um crescimento expressivo com foco no relacionamento empresa-consumidor (B2C). Martins, Kniess e Rocha (2015) salientam que os investimentos em marketing de relacionamento ocorreram muito mais por uma pressão do ambiente em que a organização está inserida, pela possibilidade de perda de mercado e pelas necessidades de fidelização de clientes e de melhorar a competitividade do que por um movimento estratégico planejado e executado de forma proativa.

Para Parvatiyar e Shelth (2001), marketing de relacionamento é uma filosofia dos negócios que busca estabelecimento, manutenção e melhoria das relações com clientes e parceiros de forma rentável para ambas as partes. Para isso, há três elementos táticos em uma estratégia de relacionamento: buscar contatos diretos com clientes, montar um banco de dados e desenvolver um sistema de serviço orientado para 0 cliente (GRONRÖOS, 2004). 


\section{A PERCEPÇÃO DE CLIENTES DE UM PROGRAMA DE RELACIONAMENTO NO VAREJO SUPERMERCADISTA}

Este relacionamento pode ser gerenciado pelas estratégias de Customer Relationship Management (CRM). Apesar do crescimento dos estudos e das discussões sobre o marketing de relacionamento e de seus avanços nas estratégias de gerenciamento do relacionamento com o cliente, o tema ainda é vítima de confusões conceituais. Demo (2015) destaca que a compreensão do que significa CRM ainda se faz limitada, pois muitas empresas não o entendem como sinônimo do marketing de relacionamento, encarandoo simplesmente como uma solução tecnológica. O CRM trata-se de uma abordagem estratégica holística para gerenciar o relacionamento com clientes e gerar valor, provendo oportunidades para o uso de dados e informações no sentido de entender o cliente e implementar melhor as estratégias de marketing de relacionamento. Tal conjunto de estratégias utiliza-se de várias ferramentas tecnológicas, inclusive de um sistema de informação denominado CRM, mas não está limitado a isso e não deve ser confundido meramente com uma solução tecnológica, já que consiste em um panorama bem mais abrangente (PAYNE, 2006). Portanto, o conceito de CRM utilizado nesta pesquisa é de um sistema holístico de estratégia que aplica os princípios do marketing de relacionamento para gerenciar o relacionamento com o cliente a longo prazo.

O CRM pode estimular a lealdade de clientes por meio de serviços personalizados, do melhor conhecimento dos clientes, segmentação de mercado e identificação de onde podem ser construídas relações lucrativas e diferenciadas da concorrência (MELO; FREITAS; MELO, 2009). Percebe-se que, mais importante do que construir, é manter esse relacionamento estreito, o que pode ser alcançado pelos seguintes fatores destacados por Morgan e Hunt (1994): confiança, comprometimento, satisfação e qualidade. Para os autores, estes fatores são mediadores do relacionamento, e trabalhá-los possibilita continuidade da relação, lealdade do consumidor e boca a boca positivo.

Segundo Vavra (1993), os relacionamentos são construídos com base na familiaridade e no conhecimento. Este autor afirma ainda que a empresa deve desenvolver um processo para receber, analisar, reconhecer e agir sobre as informações fornecidas por seus clientes, desenvolvendo um diálogo ativo com eles. Ademais, isto pode proporcionar ideias para lançamento de novos produtos, identificação e solução de possíveis erros da empresa e diminuição de aborrecimentos e de frustrações dos clientes. De acordo com Vavra (1993), 0 aumento da satisfação dos clientes por meio de interações com a empresa é o principal mecanismo para manter relacionamentos duradouros. Já para Grönroos (2004), tal satisfação do cliente e sua interatividade com a empresa passam pela oferta de recompensas aos consumidores em forma de benefícios percebidos. Este autor destaca ainda que o sucesso do marketing de relacionamento depende do compromisso e do desempenho dos funcionários. Caso contrário, a desmotivação e o desinteresse em agir com 0 cliente conforme orientado pode ter como consequência uma estratégia fracassada devido ao mau atendimento.

Sobre o desempenho dos colaboradores e a importância de seu engajamento, os estudos de Martins, Kniess e Rocha (2015) ressaltaram que, quando há o comprometimento dos profissionais de todos os níveis organizacionais, são observadas melhorias como a diminuição do volume de reclamações e 0 atendimento mais rápido aos clientes. Segundo tal pesquisa, estas melhorias refletiram-se na percepção dos clientes sobre os investimentos que as organizações realizam para aprimorar sua relação com o consumidor. Wang e Yang (2015) demonstram a impossibilidade de um CRM bem estruturado se não houver integração com as capacidades dos recursos humanos. Lorenço e Sette (2013) destacam a importância do desenvolvimento de habilidades de relacionamento dos funcionários da linha de frente para com os clientes, de forma a melhorar o valor percebido pelo cliente.

Para tal aprimoramento, dentre os diversos atributos citados pela literatura como indispensáveis à melhoria dessa relação, destaca-se a comunicação. McKenna (2002) a aponta como um dos construtos principais para se iniciar e manter relacionamentos com os consumidores, afirmando que a comunicação é a essência do atendimento ao cliente e fundamental para desenvolver relacionamentos positivos. Atualmente, essa comunicação adquire grandes dimensões no meio on-line, inclusive por redes sociais, ganhando força nesta pesquisa ao se perceber que a presença dos supermercados em redes sociais pode estreitar 0 


\section{Vívian Larissa Alves Araújo Arraes, Francisco Juanito Costa da Silva, Érico Veras Marques, Jocildo Figueiredo Correia Neto}

relacionamento com o cliente (BOWERSOX; CLOSS; COOPER, 2006).

Os estudos de Sousa et al. (2018) também indicaram que as redes sociais são uma boa via de divulgação, como propagandas e marketing em geral. Eles ressaltam que mais de $43 \%$ do público investigado afirmou adotar ações de compartilhamento de publicações empresariais. Além disso, mais de $85 \%$ dos respondentes afirmaram analisar o feedback dos demais consumidores para avaliar critérios de preço, atendimento, qualidade do produto e entrega, que já são construtos apontados na literatura de marketing de relacionamento. Sousa et al. (2018) concluem que as redes sociais são uma grande via de comunicação e interação, que proporcionam trocas de experiências relevantes entre os consumidores, ressaltando a importância e o poder de influência dessas mídias no comportamento dos consumidores e, consequentemente, nos resultados de competitividade das empresas.

Acerca deste tema, Vinerean e Opreana (2015) desenvolveram um estudo para validação de escala relacionada ao engajamento do consumidor em ambientes on-line. A pesquisa sugere que as questões de marketing de relacionamento podem ser melhor trabalhadas com foco no engajamento do consumidor no ambiente on-line. $\mathrm{O}$ acompanhamento on-line pode ajudar os gerentes a terem insights sobre os pontos focais de envolvimento dos consumidores, o que lhes dará vantagem competitiva frente aos desafios de atrair os consumidores mais relevantes, encontrar formas de reter os mais rentáveis, incentivar os consumidores fiéis na defesa da marca, além de aumentar sua frequência de compras.

Stone, Woodcock e Machtynger (2001) destacam que os clientes esperam das organizações conveniência, comunicação apropriada, status especial e privilegiado como cliente conhecido da organização, reconhecimento da história existente entre a empresa e ele, soluções rápidas e eficazes em caso de problemas, previsão adequada de suas necessidades e um diálogo profissional e amigável, sendo o diálogo a essência do CRM. É com base nestas características das expectativas do cliente quanto às empresas e em todo o referencial sobre relacionamento descrito até então, que este estudo se embasa para buscar atender seus objetivos e responder à questão problema que o incitou.

\section{Metodologia}

A presente pesquisa classifica-se como estudo caso, com abordagem analítica quantitativa. $O$ estudo de caso busca explorar, descrever e explicar um fenômeno em seu contexto (LIMA et al., 2012). Segundo Yin (1986), o estudo de caso constitui-se de uma estratégia de pesquisa que não pode ser classificada a priori como qualitativa nem quantitativa, por excelência, mas que está interessada no fenômeno. Para Stake (1999), a distinção de métodos qualitativos e quantitativos é uma questão de ênfase, já que a realidade é uma mistura de ambos. Quanto à utilização do método quantitativo em estudos de caso, Latorre, Rincón e Arnal (2003) destacam que, apesar de o estudo de caso ser visto com ênfase nas metodologias qualitativas, isso não significa que não possa contemplar perspectivas quantitativas. Yin (2005) destaca ainda que a estratégia de estudo de caso é bastante abrangente e não deve ser confundida com pesquisa qualitativa, pois tanto pode incluir as evidências quantitativas como até mesmo ficar limitada a elas.

Esta pesquisa foi realizada com os dados das percepções de clientes da cidade de Fortaleza (CE) a respeito das ações de relacionamento de uma rede de supermercados presente na região. A coleta de dados ocorreu durante os meses de novembro e dezembro de 2017, podendo caracterizar o estudo, em sua forma de coletar os dados, como transversal, já que usa uma abordagem típica de "fotografia", na qual os dados são coletados em um determinado momento (GRAY, 2012).

0 instrumento de pesquisa iniciou-se com a explicação da pesquisa e intencionou esclarecer aos respondentes que o estudo não identifica os participantes devido ao compromisso com os princípios éticos norteadores na pesquisa acadêmica. Em seguida, foi composto pela seção de descrição do perfil sociodemográfico, seguido das informações sobre a relação do cliente com o supermercado. As duas primeiras questões após a descrição sociodemográfica incluiam saber se os respondentes eram clientes assíduos do supermercado, se faziam parte do programa de relacionamento e se realizavam suas compras 


\section{A PERCEPÇÃO DE CLIENTES DE UM PROGRAMA DE RELACIONAMENTO NO VAREJO SUPERMERCADISTA}

na cidade de Fortaleza.

Assim, foram excluídos os participantes que não eram clientes e que não optaram pelo domicílio de Fortaleza, de forma a atender aos critérios de confiança da pesquisa e manter o perfil geográfico homogêneo do público-alvo. De acordo com o Instituto Brasileiro de Geografia e Estatística (IBGE), a estimativa mostra que a capital cearense é a quinta capital mais populosa do país, apontando para 2.609.716 habitantes em 2017 (IBGE, 2017), o que sugere maior confiabilidade à poupulação determinada para a pesquisa. Desta forma, dos 209 questionários inicialmente respondidos, 121 se mantiveram válidos, compondo a amostra que atende aos critérios deste estudo. Esta amostra caracacteriza-se como não-probabilística por julgamento (HAIR et al., 2005), visto que as percepções dos clientes foram coletadas em redes sociais, divulgadas para grupos específicos de clientes da empresa que se pretendia pesquisar, ou enviadas diretamente para usuários destas redes que se afirmavam clientes do supermercado em questão.

Aúltima e principal seção componente do instrumento de pesquisa abordou questões avaliativas quanto aos critérios de relacionamento e lealdade, além da ações de relacionamento realizadas pelo supermercado. Foi aplicada a escala de Likert de sete pontos, variando entre discordo totalmente a concordo totalmente, pois, em uma escala com mais pontos, maior poderá ser a precisão obtida quanto à intensidade com que a pessoa concorda ou discorda da afirmação (HAIR et al., 2005, p.187). As variáveis utilizadas mesclaram construtos e escalas advindas dos estudos de Antunes e Rita (2007), Demo e Rozzett (2013), Demo e Pessôa (2015) e Vinerean e Opreana (2015).

Foram pré-testados 15 questionários. Após as correções de incoerências, efetuou-se o compartilhamento do endereço on-line do questionário, feito pela plataforma Google Forms, por meio de redes sociais e correio eletrônico. Hair et al. (2005) destacaram diversas vantagens do uso da internet em coleta de dados, com destaque para o baixo custo, além da agilidade e flexibilidade. Para Malhotra (2006), o levantamento por internet é menos inconveniente, pois pode ser completado no tempo e no local de cada um, além de possibilitar maior rapidez de resposta e ter a capacidade de visar populações específicas.

A análise foi realizada com o auxílio do software SPSS 22 versão trial. O modelo foi desenvolvido após a remoção das informações dos 15 questionários verificados no pré-teste. As variáveis em questão foram submetidas a uma análise fatorial para a determinação de grupos de indicadores (fatores), aplicando-se posteriormente uma árvore de classificação.

A análise fatorial é uma técnica de análise multivariada de interdependência, que busca identificar fatores comuns em um conjunto de variáveis inter-relacionadas (FÁVERO et al., 2009). Assim, tal análise busca a criação de fatores que expliquem simultaneamente todos os indicadores. Já a árvore de classificação é uma das técnicas de mineração de dados mais utilizadas para categorizar dados, sendo um método adequado quando o objetivo é classificar os dados ou predizer uma saída. Seu uso fornece também uma escolha quando se busca gerar regras que podem ser facilmente entendidas, explicadas e traduzidas (LEMOS; STEINER; NIEVOLA, 2005). Assim, estes métodos auxiliam a pesquisa em seu intento de identificar as variáveis mais significativas para a gestão de relacionamento do supermercado, analisando a percepção dos clientes sobre elas, assim como perceber quais dentre elas realmente se destacam para 0 supermercado como estratégias agregadoras de competitividade.

\section{Análise das estratégias de relacionamento da empresa}

Para gerenciar as estratégias de relacionamentos, ação comum às empresas é criar programas de fidelização. $O$ termo programa de lealdade envolve uma série de iniciativas de marketing incluindo cartões de recompensas, brindes, níveis de serviço diferenciados, suporte e contato específicos, entre outros métodos que influenciem positivamente a atitude e o comportamento do consumidor em relação à marca ou à empresa, como desconto ou incentivos financeiros de curto prazo que compensam os consumidores por maior volume ou maior frequência de compras (HENDERSON; BACK; PALMATIER, 2011, p. 258). 


\section{Vívian Larissa Alves Araújo Arraes, Francisco Juanito Costa da Silva, Érico Veras Marques, Jocildo Figueiredo Correia Neto}

Segundo Blackwell, Miniard e Engel (2011), programas de fidelidade, por definição, reconhecem e recompensam os consumidores pelo seu "bom comportamento" e consistem em um esforço para aumentar fidelidade deles a uma marca de produto, serviço ou varejo. Isso possibilita conhecer os hábitos de compra dos clientes e permite à empresa personalizar a sua oferta de produtos e melhorar seu contato com os consumidores. Blackwell, Miniard e Engel (2011) reforçam ainda uma série de estatégias que as empresas podem adotar, dentre elas: fazer o marketing individualizado (one-to-one), com ações direcionadas a cada cliente de forma específica; instituir uma política de controle da qualidade total e um sistema de identificação antecipada de problemas; criar nos clientes expectativas realistas, sem promessas que não possam ser cumpridas; proprocionar garantias, além de informações sobre o uso do produto; e solicitar respostas dos consumidores, com sistema de feedback adequado, proporcionando reconhecimento e resposta às reclamações dos consumidores.

Em seus estudos, Peppers e Rogers Group (2004) analisaram práticas de relacionamento e como os programas de fidelidade podem impulsionar a estratégia da empresa e determinar mudanças de foco da organização. Segundo este estudo, os canais mais citados para o fornecimento de informações para os clientes sobre os programas de relacionamento foram: sites, informativos impressos, e-mail, central de atendimento telefônico e extrato de pontos, o que demonstra a importância da utilização das ferramentas da tecnologia da informação e comunicação (TIC) para divulgação de ações desses programas.

A adoção de tal estratégia de relacionamento torna-se ação cada vez mais indispensável e preponderante no atual contexto competitivo em varejos como o supermercadista. Para Mendes e Pendron (2014), os programas lealdade são um tópico importante hoje para a maioria dos ramos de atividade, em especial os que apresentam elevada concorrência, pois sem uma base de clientes leais, a empresa não consegue se desenvolver em seu mercado.

A empresa cujas ações são estudadas nesta pesquisa possui um histórico de pioneirismo quanto às ações de marketing de relacionamento e às estratégias integradas para gerir o relacionamento com 0 cliente, inclusive pela adoção de novas tecnologias e formas de comunicação nesse processo. Em 1993, a rede criou o primeiro canal oficial do varejo brasileiro de comunicação com o público, no intuito de ouvir e resolver os problemas dos consumidores. Durante os anos 1990, outras medidas para recuperar o mercado foram tomadas, dentre elas: implementação do código de barras, criação de um supermercado virtual e aquisição de outras redes (SANTOS, 2013).

Ainda quanto aos avanços em tecnologia para melhor relacionar-se com o cliente, em 2008, esta rede inaugurou uma loja que é referência no Brasil em tecnologia de varejo. Foram investidos mais de $R \$ 3,9$ milhões na construção desta loja conceito, com promessas de constantes evoluções, não só em novas tecnologias, mas também em relação a sortimento de produtos e serviços. O que tal loja oferece é a integração dos mais avançados equipamentos, softwares e diversas soluções tecnológicas em um ambiente diferenciado de loja. Soluções estas que possibilitaram agilizar em $30 \%$ o tempo de atendimento aos clientes (RODIGUES, 2014). Muitos desses equipamentos já estão sendo nas outras lojas da rede e ainda estão recebendo adaptações.

O programa de relacionamento foco deste estudo também é um dos mais antigos do mercado. Este programa de relacionamento, com base em informações de bancos de dados e soluções CRM, possui ofertas exclusivas, promoções e outras vantagens para os clientes cadastrados. De acordo com Riegel e Pereira (2010), o programa foi lançado em fevereiro de 2000, baseado na concessão de brindes temáticos e esporádicos, além de ofertas exclusivas. 0 cadastro de clientes nos primeiros anos foi tão grande que logo se percebeu a necessidade de identificar os melhores clientes já cadastrados e criar ações de reconhecimento diferenciadas. Em 2006, foi revista a estrutura do programa para criar uma experiência única de valor com a marca para estes clientes. Realizou-se um piloto do novo programa por um ano em seis lojas específicas, obtendo excelentes resultados e possibilitando implantação no restante da rede.

A base de dados e a inteligência de análise do programa são atrativas para os fornecedores, assim eles 


\section{A PERCEPÇÃO DE CLIENTES DE UM PROGRAMA DE RELACIONAMENTO NO VAREJO SUPERMERCADISTA}

buscam desenvolver parcerias segmentadas com o objetivo de alcançar seus consumidores de forma estratégica. Tais parcerias visam à entrega de um benefício exclusivo para o cliente, podendo ser uma oferta, um conteúdo diferenciado, a apresentação de um lançamento ou um convite à experimentação. Há também diversos pontos de contato com o cliente: material de ponto de venda, todos os funcionários da loja que receberam treinamento, o site, as redes sociais, a comunicação em e-mail marketing, mala direta, call center, tablóide, filmes e eventos institucionais; são esses os pontos de contato mais facilmente identificados. Há personzalização por segmentos de clientes, no intuito de aumentar envolvimento e potencializar a influência nas escolhas do consumidor, estimulando que ele seja um embaixador da marca em sua rede de contatos (RIEGEL; PEREIRA, 2010).

A estratégia mais recente quanto às soluções tecnológicas e de aproximação com o cliente é o aplicativo para smartphone que possui descontos exclusivos e segmentados para os clientes cadastrados, com produtos em oferta conforme seus hábitos de compra. Há, no mínimo, 30 ofertas renovadas a cada duas semanas. Isso mostra a utilização dos dados dos softwares de CRM para, de fato, desenvolver ações voltadas ao conceito holístico da gestão de relacionamento com o cliente. Para utilizar essa solução, 0 cliente baixa o aplicativo gratuitamente em seu smartphone e clica nas ofertas de seu interesse para ativálas, bastando ir à loja e se identificar no caixa via CPF para a compra do produto com desconto, ou mesmo realizar a compra na loja on-line. 0 aplicativo permite ainda obter informações do produto por meio da leitura do código de barras e possui localizador para indicar a loja da rede mais próxima, além de permitir a elaboração de lista de compras.

Aqui se percebe um esforço estratégico de gerenciamento do relacionamento com o cliente, ações que vão ao encontro das ideias de Mendes e Pendron (2014), quando salientam que os programas de fidelidade precisam ser dinâmicos e englobar constantemente novas ideias, práticas e tecnologias devido às mudanças constantes do mercado e dos próprios clientes, cada vez mais exigentes. Além disso, a comunicação com os clientes também é realizada via e-mail marketing, portal eletrônico e interação via diversas redes sociais, com uma comunicação integrada nos canais. Ao se analisar este programa de relacionamento, é possível perceber que são aplicados diversos conceitos descritos como importantes na literatura do marketing de relacionamento. Identifica-se aqui claramente: a oferta de benefícios exclusivos e bonificações em favor do cliente cadastrado no programa (GRÖONROS, 2004); o uso do banco de dados para segmentar clientes e direcionar esforços promocionais (VAVRA, 1993; STONE; WOODCOCK; MACHTYNGER, 2001); o uso da tecnologia em favor do estreitamento desta relação e desenvolvimento de experiências personalizadas e únicas, em um trabalho voltado a melhorar a comunicação com o cliente e executá-la por diferentes canais (MCKENNA, 2002; PAYNE, 2006).

Com isso, é possível observar as ações estratégicas desenvolvidas pela marca em favor do melhor relacionamento com o cliente. Mas é então que se chega às inquietações que incitaram esta pesquisa. Quais dessas ações são realmente percebidas? Como o cliente as percebe/interage com elas? Elas realmente agregam valor? Será que as ações mais simples são bem feitas e "surtem efeito"? Quais são as ações mais importantes para realmente incentivar a lealdade desse cliente e que devem ser bem cultivadas no programa de relacionamento? É neste momento que a presente pesquisa intenciona direcionar as possíveis respostas para estes questionamentos e, assim, atender aos objetivos propostos. Realiza-se tal intento no item subsequente, pela análise da percepção dos clientes frente às ações da empresa, com base nos construtos já apontados pela literatura e aqui apresentados anteriormente.

\section{Resultados e discussão}

Inicialmente, apresenta-se o perfil sócio demográfico da amostra de clientes na Tabela 1. Posteriormente, apresentam-se as estatísticas descritivas para as variáveis na Tabela 2. Para analisar a utilização dos participantes em relação ao uso do programa de relacionamento, foram avaliados os dados com base nestas descrições. 


\section{Vívian Larissa Alves Araújo Arraes, Francisco Juanito Costa da Silva, Érico Veras Marques, Jocildo Figueiredo Correia Neto}

\begin{tabular}{l|l|l|l}
\hline \multirow{3}{*}{$\begin{array}{l}\text { Perfil } \\
\text { Sexo }\end{array}$} & Feminino & $\underline{\mathbf{N}}$ & $\underline{\text { Percentual }}$ \\
\cline { 2 - 4 } & Masculino & 81 & $66,94 \%$ \\
\hline \multirow{5}{*}{ Faixa Etária } & $15-20$ anos & 40 & $33,06 \%$ \\
\cline { 2 - 4 } & $21-35$ anos & 3 & $2,48 \%$ \\
\cline { 2 - 4 } & $36-45$ anos & 81 & $66,94 \%$ \\
\cline { 2 - 4 } & $46-55$ anos & 19 & $15,70 \%$ \\
\cline { 2 - 4 } & $56-65$ anos & 11 & $9,09 \%$ \\
\cline { 2 - 4 } & acima de 65 anos & 5 & $4,13 \%$ \\
\hline \multirow{4}{*}{ Escolaridade } & Ensino Médio completo/Incompleto & 6 & $1,65 \%$ \\
\cline { 2 - 4 } & Ensino Superior completo/Incompleto & 52 & $42,96 \%$ \\
\cline { 2 - 4 } & Pós-graduação & 63 & $52,07 \%$ \\
\hline \multirow{4}{*}{ Renda } & Até 1 salário mínimo & 5 & $4,13 \%$ \\
\cline { 2 - 4 } Familiar & 2 a 3 salários mínimos & 30 & $24,79 \%$ \\
\cline { 2 - 4 } & 4 a 5 salários mínimos & 30 & $24,79 \%$ \\
\cline { 2 - 4 } & Acima de 5 salários mínimos. & 56 & $46,28 \%$ \\
\hline
\end{tabular}

Tabela 1 - Perfil sócio demográfico dos participantes

Fonte: dados da pesquisa

Percebe-se, a partir da Tabela 1, a predominância do público feminino, com idade entre 21 e 35 anos, pósgraduados e com renda superior a 5 salários mínimos. No tocante à ocupação, 51\% (62) dos participantes são funcionários de empresas privadas ou públicas, $23 \%$ (28) são estudantes e as demais categorias apresentam ocupações diversas, reunindo os $26 \%$ (31) restantes da amostra. Isso demonstra que o público da empresa analisada nesta pesquisa concentra-se em adultos jovens, com escolaridade e classe social elevadas, o que confere com o perfil de clientes que a própria empresa descreve possuir e que explica determinadas ações de segmentação, ligadas, por exemplo, ao sortimento de produtos e à localização.

Fez-se também uma análise de estatísticas descritivas das percepções por questão interrogada, na qual foram calculados a média, o desvio padrão e o coeficiente de variação para cada item, conforme Tabela 2.

\begin{tabular}{l|l|l|l|l}
\hline$\underline{\text { Variáveis }}$ & $\mathbf{N}$ & Média & $\begin{array}{l}\text { Desvio } \\
\text { Padrão }\end{array}$ & $\begin{array}{l}\text { Coeficiente } \\
\text { de Variação }\end{array}$ \\
\hline Meu apego emocional à marca é: & 121 & 5,0 & 2,8 & 0,6 \\
\hline Estou satisfeito com a personalização do atendimento. & 121 & 5,6 & 2,0 & 0,4 \\
\hline $\begin{array}{l}\text { Estou satisfeito com a qualidade dos produtos/serviços prestados por este } \\
\text { supermercado. }\end{array}$ & 121 & 6,5 & 1,6 & 0,2 \\
\hline Eu prefiro este supermercado em relação aos seus concorrentes. & 121 & 4,5 & 2,0 & 0,5 \\
\hline Eu me sinto um cliente importante para este supermercado. & 121 & 4,1 & 2,1 & 0,5 \\
\hline $\begin{array}{l}\text { A publicidade realizada por este supermercado, especialmente em redes } \\
\text { sociais e meios eletrônicos, condiz com o que ele realmente oferece. }\end{array}$ & 121 & 5,6 & 1,9 & 0,3 \\
\hline Este supermercado merece a minha confiança. & 121 & 6,0 & 1,6 & 0,3 \\
\hline Este supermercado me oferece atendimento personalizado. & 121 & 4,5 & 2,1 & 0,5 \\
\hline $\begin{array}{l}\text { Os preços dos produtos deste supermercado são justos (relação custo/ } \\
\text { benefício). }\end{array}$ & 121 & 4,3 & 2,1 & 0,5 \\
\hline \begin{tabular}{l} 
Este supermercado possui uma imagem positiva/credibilidade no mercado. \\
\hline
\end{tabular} & 121 & 6,6 & 1,4 & 0,2 \\
\hline
\end{tabular}




\section{A PERCEPÇÃO DE CLIENTES DE UM PROGRAMA DE RELACIONAMENTO NO VAREJO SUPERMERCADISTA}

\begin{tabular}{|c|c|c|c|c|}
\hline $\begin{array}{l}\text { Conheço ações sociais e estratégias de preservação do meio ambiente } \\
\text { deste supermercado. }\end{array}$ & 121 & 4,1 & 2,5 & 0,6 \\
\hline Este supermercado possui variedade de produtos ou marcas. & 121 & 6,8 & 1,6 & 0,2 \\
\hline $\begin{array}{l}\text { Os funcionários deste supermercado estão capacitados para atender os } \\
\text { clientes. }\end{array}$ & 121 & 6,4 & 1,5 & 0,2 \\
\hline $\begin{array}{l}\text { Este supermercado recompensa minha fidelidade (ex.: descontos nas } \\
\text { compras, facilidade de pagamento, etc). }\end{array}$ & 121 & 5,2 & 2,2 & 0,4 \\
\hline Este supermercado está presente em redes sociais. & 121 & 5,3 & 2,1 & 0,4 \\
\hline $\begin{array}{l}\text { Este supermercado oferece atendimento personalizado nos seus canais de } \\
\text { relacionamento com os cidadãos. }\end{array}$ & 121 & 4,7 & 1,9 & 0,4 \\
\hline Este supermercado considera minhas dúvidas, sugestões e reclamações. & 121 & 4,7 & 1,9 & 0,4 \\
\hline Este supermercado consegue identificar minhas necessidades. & 121 & 4,9 & 2,0 & 0,4 \\
\hline Este supermercado se comunica frequentemente com seus clientes. & 121 & 4,9 & 2,2 & 0,4 \\
\hline $\begin{array}{l}\text { Sempre que o serviço não é prestado como eu pretendo, sugiro formas de } \\
\text { alteração. }\end{array}$ & 121 & 3,8 & 2,4 & 0,6 \\
\hline Este supermercado encoraja seus clientes a apresentarem sugestões. & 121 & 4,2 & 2,2 & 0,5 \\
\hline Os empregados resolvem qualquer situação ou problema que surja. & 121 & 5,0 & 2,0 & 0,4 \\
\hline As instalações deste supermercado são visualmente atrativas. & 121 & 6,2 & 1,8 & 0,3 \\
\hline $\begin{array}{l}\text { Seguir a marca em redes sociais estimula meu interesse em aprender mais } \\
\text { sobre a empresa e seus produtos. }\end{array}$ & 121 & 4,8 & 2,4 & 0,5 \\
\hline $\begin{array}{l}\text { Sigo a marca deste supermercado nas redes sociais porque me chama a } \\
\text { atenção. }\end{array}$ & 121 & 3,4 & 2,4 & 0,7 \\
\hline Acho que as postagens da marca nas redes sociais são muito úteis. & 121 & 4,5 & 2,3 & 0,5 \\
\hline Acho que as postagens da marca nas redes sociais são divertidas. & 121 & 3,9 & 2,1 & 0,6 \\
\hline $\begin{array}{l}\text { Estou disposto a colaborar em diferentes iniciativas nas redes sociais desta } \\
\text { Marca para desenvolvimento de novos produtos / serviços / recursos. }\end{array}$ & 121 & 4,0 & 2,4 & 0,6 \\
\hline Eu costumo curtir as postagens desta marca nas redes sociais. & 121 & 3,0 & 2,3 & 0,8 \\
\hline
\end{tabular}

Tabela 2 - Estatísticas descritivas das percepções dos participantes.

Fonte: dados da pesquisa

As maiores médias apresentadas foram em itens relacionados à variedade (mix) de produtos, qualidade dos produtos e serviços, atendimento, imagem e credibilidade da marca, o que demonstra vários pontos a favor da marca em relação a este quesitos. Já as menores médias foram as de itens relacionados às redes sociais da marca, tanto participação da marca nas redes como acompanhamento dos clientes. Isso demonstra que a marca deixa a desejar quanto à comunicação com os clientes via redes sociais, levando à conclusão de que ela não é bem percebida pelo cliente ou não tem a frequência e retorno adequados.

Ao se analisarem os coeficientes de variação, foi possível perceber uma baixa dispersão das respostas. Portanto, o desvio-padrão não apresentou altas discrepâncias em nenhuma das variáveis, permitindo-se manter todas.

Em seguida, para melhor entender os dados, foi realizada uma análise fatorial (AF), na tentativa de reunir todos os indicadores em uma única análise de dados. Foram então realizados testes para observar a possibilidade da aplicação de tal análise. $O$ teste de Kaiser-Meyer-Olkin (Measure of Sampling Adequacy MSA) indica o grau de explicação dos dados a partir dos fatores encontrados na AF. Caso o MSA indique um grau de explicação menor do que 0,50 , significa que os fatores encontrados na AF não conseguem descrever satisfatoriamente as variações dos dados originais (HAIR et al., 2005). Assim, esta pesquisa 


\section{Vívian Larissa Alves Araújo Arraes, Francisco Juanito Costa da Silva, Érico Veras Marques, Jocildo Figueiredo Correia Neto}

indicou adequação para a AF com poder de explicação de 0,899 entre os fatores e as variáveis indicadas. $O$ teste de esfericidade de Bartlett, que indica se existe relação suficiente entre os indicadores para aplicação da AF, no caso desta pesquisa, foi positivo, mostrando a possibilidade de aplicação. Esta afirmativa da adequação e continuidade da AF foi reiterada pelo valor de Sig. (teste de significância), que se mostrou inferior a 0,05, pois, se o valor de Sig. atingir 0,10, a AF é desaconselhável (HAIR et al., 2005).

Após confirmar a adequação de utilização da análise fatorial, observaram-se as comunalidades, que expressam o poder de explicação de cada variável. Os itens de maiores comunalidades foram: "Este supermercado considera minhas dúvidas, sugestões e reclamações" $(0,797)$; "Sigo a marca deste supermercado nas redes sociais porque me chama a atenção" $(0,794)$; e "As instalações deste supermercado são visualmente atrativas" (0,762).

$\mathrm{Na}$ Tabela 3, apresentam-se os fatores gerados pela AF, que explicam $71,5 \%$ das variações totais dos dados. Com relação a esse indicativo e com uma forte relação entre os fatores e algumas variáveis, o modelo utilizou-se de uma extração por análise das componentes principais e rotação Varimax.

\begin{tabular}{|c|c|c|c|c|c|c|}
\hline \multirow{2}{*}{$\underline{\text { VARIÁVEIS }}$} & \multicolumn{6}{|c|}{ FATORES } \\
\hline & 1 & 2 & 3 & 4 & 5 & 6 \\
\hline Meu apego emocional à marca é: &, 634 & & & & & \\
\hline Estou satisfeito com a personalização do atendimento. & 689 & & & & & \\
\hline $\begin{array}{l}\text { Estou satisfeito com a qualidade dos produtos/serviços prestados por este, } \\
\text { supermercado. }\end{array}$ & ,706 & & & & & \\
\hline Eu prefiro este supermercado em relação aos seus concorrentes. & 771 & & & & & \\
\hline Eu me sinto um cliente importante para este supermercado. & 652 & & & & & \\
\hline $\begin{array}{l}\text { A publicidade realizada por este supermercado, especialmente em redes sociais } \\
\text { e meios eletrônicos, condiz com o que ele realmente oferece. }\end{array}$ &, 683 & & & & & \\
\hline Este supermercado merece a minha confiança. & ,728 & & & & & \\
\hline Este supermercado me oferece atendimento personalizado. & 634 & & & & & \\
\hline $\begin{array}{l}\text { Os preços dos produtos deste supermercado são justos (relação custo/, } \\
\text { benefício). }\end{array}$ & ,749 & & & & & \\
\hline Este supermercado consegue identificar minhas necessidades. & 603 & & & & & \\
\hline $\begin{array}{l}\text { Seguir a marca em redes sociais estimula meu interesse em aprender mais sobre } \\
\text { a empresa e seus produtos. }\end{array}$ & & 628 & & & & \\
\hline $\begin{array}{l}\text { Sigo a marca deste supermercado nas redes sociais porque me chama a } \\
\text { atenção. }\end{array}$ & &, 790 & & & & \\
\hline Acho que as postagens da marca nas redes sociais são muito úteis. & & 830 & & & & \\
\hline Acho que as postagens da marca nas redes sociais são divertidas. & &, 783 & & & & \\
\hline $\begin{array}{l}\text { Estou disposto a colaborar em diferentes iniciativas nas redes sociais desta } \\
\text { Marca para desenvolvimento de novos produtos / serviços / recursos. }\end{array}$ & &, 755 & & & & \\
\hline Eu costumo curtir as postagens desta marca nas redes sociais. & &, 743 & & & & \\
\hline $\begin{array}{l}\text { Este supermercado recompensa minha fidelidade (ex.: descontos nas compras, } \\
\text { facilidade de pagamento, etc). }\end{array}$ & & &, 605 & & & \\
\hline
\end{tabular}




\section{A PERCEPÇÃO DE CLIENTES DE UM PROGRAMA DE RELACIONAMENTO NO VAREJO SUPERMERCADISTA}

\begin{tabular}{|c|c|c|c|c|}
\hline Este supermercado está presente em redes sociais. & ,608 & & & \\
\hline $\begin{array}{l}\text { Este supermercado oferece atendimento personalizado nos seus canais de } \\
\text { relacionamento com os cidadãos. }\end{array}$ & ,655 & & & \\
\hline Este supermercado considera minhas dúvidas, sugestões e reclamações. & ,691 & & & \\
\hline Este supermercado se comunica frequentemente com seus clientes. & ,609 & & & \\
\hline Os empregados resolvem qualquer situação ou problema que surja. &, 547 & & & \\
\hline $\begin{array}{l}\text { Sempre que o serviço não é prestado como eu pretendo, sugiro formas de } \\
\text { alteração. }\end{array}$ & &, 821 & & \\
\hline Este supermercado encoraja seus clientes a apresentarem sugestões. & &, 571 & & \\
\hline Este supermercado possui uma imagem positiva/credibilidade no mercado. & & &, 589 & \\
\hline Este supermercado possui variedade de produtos ou marcas. & & & 824 & \\
\hline Os funcionários deste supermercado estão capacitados para atender os clientes. & & & 609 & \\
\hline $\begin{array}{l}\text { Conheço ações sociais e estratégias de preservação do meio ambiente deste } \\
\text { supermercado. }\end{array}$ & & & &,- 521 \\
\hline As instalações deste supermercado são visualmente atrativas. & & & &, 595 \\
\hline
\end{tabular}

Tabela 3 - Matriz rotacionada com os fatores

Fonte: dados da pesquisa

A partir da análise dos fatores, foi possível classificá-los conforme as características das variáveis que os compõem. 0 fator 1, composto por dez variáveis, pode ser analisado como Valor Percebido pelo Cliente. 0 fator 2, com seis variáveis, define-se como Presença em Redes Sociais. 0 fator 3 , também com seis variáveis, refere-se à Comunicação com o Cliente. 0 fator 4 , com duas variáveis, pode ser denominado como Sugestões de Melhoria. Já o fator 5 , com três variáveis, pode ser intitulado como Imagem de Marca. Por fim, o fator 6, com duas variávies, pode ser demilitado como Diferenciais Diversos.

Percebe-se, ao analisar a tabela, maior concentração de variáveis nos três primeiros fatores, o que destaca a importância de construtos já indicados pela literatura de marketing de relacionamento e citados ao longo do referencial teórico desta pesquisa. O que o cliente atribui importância em maior grau, e de fato é percebido com diferencial, está relacionado, no fator 1: ao potencial de atendimento e ao grau de personalização e aproximação que a marca oferece ao atendê-lo; à satisfação de suas expectativas com identificação de suas necessidades; e à qualidade dos produtos. Bastante importante nessa percepção também é o que se vê destacado no fator 2, demonstrando a importância da comunicação direta com o cliente e da utilização de novos canais proporcionados pelo relacionamento no meio on-line. $O$ fator 3 mostra que a boa comunicação e um adequado feedback com o cliente é preponderante para o sucesso das estratégias da marca, fato complementado pelo fator 4, que mostra a importância de que a marca leve em conta as sugestões de melhorias do cliente. As implicações advindas destes fatores corroboram com as ideias de uma vasta literatura, indo ao encontro das afirmações de autores como Morgan e Hunt (1994), Stone, Woodcock e Machtynger (2001), McKenna (2002) e Gronröos (2004).

0 fator 5 , por sua vez, demonstra a necessidade de se cuidar das estratégias básicas de marketing e do posicionamento para desenvolver a imagem de marca, além da importância da capacitação dos funcionários, assim como seu bom relacionamento com o cliente. E o fator 6 destaca que outras variáveis, 


\section{Vívian Larissa Alves Araújo Arraes, Francisco Juanito Costa da Silva, Érico Veras Marques, Jocildo Figueiredo Correia Neto}

como o visual do ambiente de loja, também é percebido como uma estratégia forte neste segmento. Tais achados confirmam o que foi apresentado pelos estudos de autores como Vavra (1993) e Martins, Kniess e Rocha (2015).

Outra questão destacada pelo fator 6 , e que chama a atenção, é perceber que as ações socioambientais também são tidas como importantes pelo cliente. Isso se sobressai em um ambiente no qual o consumidor é cada vez mais exigente e bem informado, sendo característica dos novos consumidores e de um mercado mais preocupado com ações socioambientais. Tais aspectos exigem que a marca perceba a importância de atrelar as ações de relacionamento às novas exigências do cliente e às mudanças no comportamento de consumo. Isso vai ao encontro das ideias de Mendes e Pendron (2014), ao destacarem a necessidade de dinamizar as ações de relacionamento, agregando ideias que acompanhem as mudanças do mercado e que atendam às novas exigências dos clientes.

$\mathrm{Na}$ rede de supemercados foco desta pesquisa, são desenvolvidas diversas ações voltadas ao meio ambiente, que não foram descritas neste estudo porque não são apresentadas pela marca especificamente como parte das suas estratégias de relacionamento. Tanto que tais ações não possuem divulgação bem realizada em seus canais de comunicação com o cliente. Assim, neste estudo, as questões ambientais mostraram-se importantes, mas as ações relativas ao supermercado não foram bem percebidas pelo cliente, que não pode enxergá-las como um diferencial do programa de relacionamento porque não as conhece. Novamente, ressalta-se a importância de se comunicar os valores da empresa aos clientes e divulgar ações diferenciadas para agregar valor à imagem de marca.

Após a delimitação dos fatores, a análise prossegue por meio de outro método estatístico que proporciona robustez e possibilita o alcance dos objetivos estabelecidos. A utilização do segundo método aplicado pode facilitar e viabilizar resultados consistentes em pesquisas com foco quantitativo (SILVA et al, 2017). Tal técnica de análise foi a árvore de classificação, pelo método CHAID (Chi-squared Automatic Interaction Detection). Também chamada de árvore de decisão, esta é uma técnica adequada quando o objetivo é classificar os dados ou predizer uma saída. Seu uso é conveniente para categorizar dados, além de fornecer uma escolha quando se busca gerar regras que podem ser facilmente entendidas, explicadas e traduzidas (LEMOS; STEINER; NIEVOLA, 2005). Tal método, em cada passo, escolhe a variável independente (preditora) que possui a interação mais forte com a variável dependente. As categorias de cada preditor são mescladas se elas não forem significativamente diferentes em relação à variável dependente (IBM, 2018). A popularidade das árvores de classificação e regressão se deve à simplicidade de interpretação e à boa capacidade de ajustamento que geralmente proporcionam (REBOUÇAS, 2011). Obteve-se, neste estudo, a seguinte árvore de classificação.

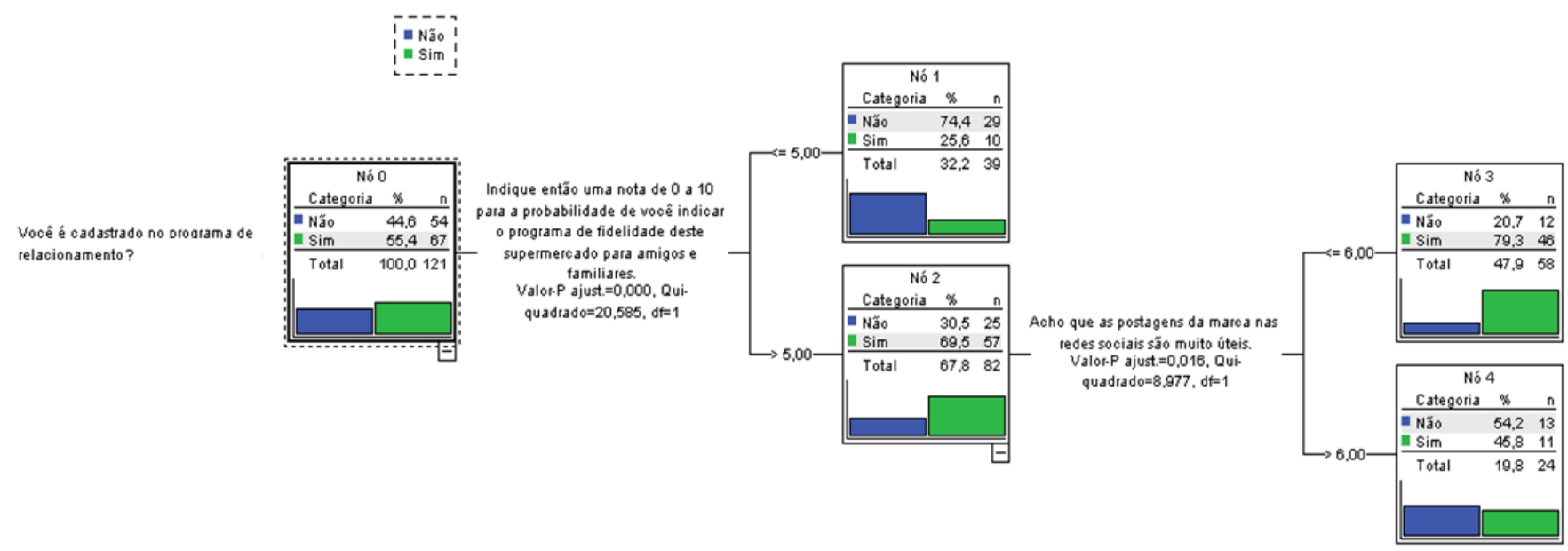

Figura 1 - Árvore de Classificação

Fonte: dados da pesquisa 


\section{A PERCEPÇÃO DE CLIENTES DE UM PROGRAMA DE RELACIONAMENTO NO VAREJO SUPERMERCADISTA}

Para a árvore gerada, utilizaram-se as respostas dos 121 participantes da pesquisa. Como variável dependente, utilizou-se a pergunta: Você é cadastrado no programa de relacionamento? Foram então encontradas diferenças significativas nas respostas das questões: "Indique então uma nota de 0 a 10 para a probabilidade de você indicar o programa de fidelidade deste supermercado para amigos e familiares" e "Acho que as postagens da marca nas redes sociais são muito úteis". A árvore gerada classifica corretamente $72,7 \%$ dos indivíduos, com um erro padrão da validação cruzada de 0,045 . Para todos os nós, observa-se um Sig. inferior a 0,02. A classificação aponta para o nó 3, em que há diferenças de 4 vezes entre os respondentes que afirmaram fazer parte do programa acharem que as postagens nas redes sociais são úteis. Além disso, este público apresenta uma probabilidade de indicação superior a 50\% (>5).

Assim, em uma análise sintética dos resultados da árvore, destaca-se que a maioria dos clientes com maior propensão a indicar participação no programa de relacionamento a amigos e familiares (ou seja, que enxergam vantagens no programa e costumam se relacionar com a marca), considera importantes as postagens da marca em redes sociais. Isso ressalta a necessidade do investimento da marca em seu programa de relacionamento, assim como a necessidade de melhor comunicação com o público via redes sociais. Destaca-se então, novamente, a importância da comunicação com o cliente e do acompanhamento da evolução frente às exigências do público, possibilitando o desenvolvimento de canais diretos que gerem interatividade. Assim, tais resultados corroboram com os achados das pesquisas de McKenna (2002), Peppers e Rogers Group (2004) e Bowersox, Closs e Cooper (2006), sugerindo que os esforços da empresa em suas ações de relacionamento são importantes e bem percebidos pelos clientes. Mas destaca-se a necessidade de bem gerir os conteúdos e aprimorar o relacionamento da marca com os clientes via redes sociais, utilizando assim as novas tecnologias a seu favor, como já ressaltado por Sousa et al. (2018), Vinerean e Opreana (2015), Payne (2006), Martins, Kniess e Rocha (2015) e Wang e Yang (2015).

\section{Considerações finais}

O presente trabalho procurou entender de que forma as ações de gerenciamento do relacionamento dos clientes de um supermercado é percebido por estes consumidores e quais dessas estratégias são de fato relevantes para eles. A pesquisa atingiu seus objetivos, uma vez que foi possível analisar as estratégias de marketing de relacionamento praticadas pela marca e a percepção de seus clientes sobre elas. A pesquisa de campo ratificou o que foi descrito na teoria e em estudos anteriores relacionados ao tema (MORGAN; HUNT, 1994; STONE; WOODCOCK; MACHTYNGER, 2001; MCKENNA, 2002; LORENÇO; SETTE, 2013; WANG; YANG, 2015; DEMO et al., 2015), por confirmar que fatores básicos como bom atendimento, personalização, comunicação efetiva, mix de produtos, confiança e qualidade têm importância fundamental para o desenvolvimento de estratégias de relacionamento com o cliente e para a sua percepção de valor sobre a marca. Assim, as empresas não podem descuidar destes quesitos e devem trabalhar para que tais critérios sejam bem desenvolvidos, o que é um passo bastante importante para o estímulo à lealdade do cliente.

No entanto, a principal contribuição deste estudo relaciona-se à comprovação da importância dos canais de comunicação direta e efetiva com o cliente, uma vez que, no atual contexto mercadológico, as redes sociais possuem papel preponderante na comunicação com o cliente e no sucesso das ações de CRM. Isso corrobora com os estudos de McKenna (2002) e Payne (2006), além de dar sustentação ao que enfatizam Bowersox, Closs e Cooper (2006), Martins, Kniess e Rocha (2015), Vinerean e Opreana (2015), Martins, Kniess e Rocha (2015) e Sousa et al. (2018), quando sugerem a importância da presença em redes sociais e que isso pode estreitar o relacionamento com o cliente, incentivando seu engajamento com a marca. Assim, tais achados da pesquisa revertem-se em importantes contribuições gerenciais do estudo, não somente destacando a necessidade de se cuidar dos critérios básicos de atenção ao cliente, já abordados na literatura como passos essenciais ao bom relacionamento do consumidor com a empresa e ao estímulo de sua lealdade, mas também evidenciando a importância de se aliar estratégias de tecnologia da informação e da comunicação nas ações de marketing de relacionamento, em especial via redes sociais. 
Outro achado importante refere-se à percepção do cliente quanto às ações socioambientais da empresa, que se destacou como fator válido para melhorar o relacionamento com o consumidor. Aqui se encontra importante contribuição acadêmica do estudo, no que se enfatiza a necessidade e relevância dos estudos que aliam comportamento do consumidor e questões sustentáveis. Sugere-se, assim, aprofundar este tema em pesquisas futuras, de forma a analisar as ações ligadas à sustentabilidade e como os clientes as percebem, observando sua interferência neste relacionamento. Tal proposta enriqueceria os estudos em marketing, tanto se aplicada no mesmo contexto, como se aplicada em outros segmentos de mercado e localidades diversas.

A presente pesquisa tem como limitações o período em que foi realizada e a especificação da região geográfica, o que limita o potencial de generalização dos seus achados. Sugere-se replicar esta pesquisa em outras realidades de mercado, bem como em diferentes regiões, com períodos de tempo e amostras maiores e probabilísticas, assim como em outros segmentos, para analisar se o comportamento dos dados difere devido ao contexto de aplicação. Espera-se, assim, que este estudo contribua para a ampliação do conhecimento sobre marketing de relacionamento e para o incentivo a novas pesquisas na área, de forma a ajudar as empresas a realizarem ações estratégicas de relacionamento com o cliente que sejam mais eficazes, gerando bons resultados em sua competitividade através do sucesso de seu CRM.

\section{Referências}

ABRAS. Vendas desaceleram, mas acumulam alta de $0,90 \%$ no ano. Abras Economia - Departamento de Economia e Pesquisa, n. 82, 30 de novembro de 2017. Disponível em: http://abras.com.br/pdf/abras_economia_82.pdf. Acesso em: 03 dez. 2017.

ANTUNES, J.; RITA, P. O marketing relacional e a fidelização de clientes: estudo aplicado ao termalismo português. Economia Global e Gestão, v.12 n.2, pp.109-132, Lisboa, 2007.

BERRY, L. Relationship marketing: emerging perspectives of service marketing. Chicago. American Marketing Association, p. 25-28, 1983.

BLACKWELL, R. D.; MINIARD, P. W.; ENGEL, J. F. Comportamento do consumidor. 9.ed. Tradução técnica Eduardo Teixeira Ayrosa (coord.). - São Paulo: Cengage Learning, 2011.

BOWERSOX, D. J.; CLOSS, D. J.; COOPER, M. B. Gestão logística de cadeias de suprimentos. São Paulo: Bookman, 2006

CERIBELI, H. B.; CERIBELI, R. F.; MERLO, E. M. Implementando um programa de relacionamento com o cliente: um estudo de caso no varejo brasileiro. Revista de Estudos Sociais, ano 12, n. 23, v. 1, pp. 73-88, 2010.

DEMO, G.; PONTE, V. Marketing de relacionamento (CRM): estado da arte e estudos de casos. São Paulo: Atlas, 2008.

DEMO, G.; ROZZETT, K. Customer Relationship Management scale for the business-to consumer market: exploratory and confirmatory validation and models comparison. International Business Research, v. 6, p. 29-42, 2013.

DEMO, G. (Org.). Marketing de relacionamento e comportamento do consumidor: estado da arte, produção nacional, novas medidas e estudos empíricos. São Paulo: Atlas, 2015.

DEMO, G.; FOGAÇA, N.; PONTE, V.; FERNANDES, T.; CARDOSO, H. Marketing de Relacionamento (CRM): Estado da Arte, Revisão Bibliométrica da Produção Nacional de Primeira Linha, Institucionalização da Pesquisa no Brasil e Agenda de Pesquisa. Revista de Administração Mackenzie, v. 16, n. 5, 2015.

DEMO, G.; PESSÔA, R. CRM na administração pública: desenvolvimento e validação de uma Escala de Relacionamento com o Cidadão (ERCi). Rev. Adm. Pública, v. 49, n. 3, p. 677-697, maio/jun. 2015. 


\section{A PERCEPÇÃO DE CLIENTES DE UM PROGRAMA DE RELACIONAMENTO NO VAREJO SUPERMERCADISTA}

FÁVERO, L. P. L.; BELFIORE, P. P.; SILVA, F. L.; CHAN, B. L. Análise de dados: Modelagem multivariada para tomada de decisões. Rio de Janeiro: Elsevier, 2009.

FARIA, L. H. L.; GIULIANI, A. C.; PIZZINATTO, N. K.; SPERS, V. R. E. 20 anos de publicações sobre marketing de relacionamento no Brasil: uma análise da produção acadêmica de 1992 a 2012 . Brazilian Journal of Marketing - BJM Revista Brasileira de Marketing - ReMark. v., 13, n. 1, jan./mar. 2014.

GERSON, R. A. A excelência no atendimento a clientes. Rio de Janeiro: Qualitymark, 1999.

GORDON, I. Marketing de relacionamento: estratégias, técnicas e tecnologias para conquistar clientes e mantê-los para sempre. São Paulo: Futura, 2002.

GRAY, D. E. Pesquisa no mundo real. 2. ed. Porto Alegre: Penso, 2012.

GRÖNROOS, C. Marketing: gerenciamento e serviços. 3.ed. Rio de Janeiro: Elsevier, 2004.

HAIR JR., J. F.; ANDERSON, R. E.; TATHAM, R. L.; BLACK, W. C. Análise multivariada de dados. 5. ed. Porto Alegre: Bookman, 2005.

HENDERSON, M. C.; BECK, J. T.; PALMATIER, R. W. Review Theoretical underpinnings of loyalty programs. Journal of Consumer Psychology, n. 21, 2011, p.p. 256-276.

IBM. IBM SPSS Software Trial Version. 2018. Disponível em: <http://www.ibm.com /software/analytics/spss/.>. Acesso em: 01 mar. 2018.

INSTITUTO BRASILEIRO DE GEOGRAFIA E ESTATISTICA (IBGE). Estimativa da População 2017. Disponível em: <http://cod.ibge.gov.br/2wqft>. Acesso em 10 out 2017.

LEMOS, E. P.; STEINER, M. T. A.; NIEVOLA, J. C. Análise de crédito bancário por meio de redes neurais e árvores de decisão : uma aplicação simples de data mining. Revista de Administração, v. 40, n. 3, p. 225234, 2005.

LIMA, J. P. C.; ANTUNES, M. T. P.; MENDONÇA NETO, O. R.; PELEIAS, I. R. Estudos de caso e sua aplicação: proposta de um esquema teórico para pesquisas no campo da contabilidade. Revista de Contabilidade e Organizações, v. 6, n. 14, p. 127-144, 2012.

LORENÇO, C. D. S.; SETTE, R. S. Marketing de relacionamento em empresas varejistas: aspectos positivos e negativos. Revista Brasileira de Marketing, v. 12, n. 3, p. 152-178, 2013.

MALHOTRA, N. K. Pesquisa de marketing:uma orientação aplicada. 4.ed. Porto Alegre: Bookman, 2006.

MARTINS, C. B.; KNIESS, C. T.; ROCHA, R. A. Um estudo sobre o uso de ferramentas de gestão do marketing de relacionamento com o cliente. Brazilian Journal of Marketing - BJM Revista Brasileira de Marketing - ReMark. v., 14, n. 1. p. 59 - 71, jan./mar. 2015.

MENDES, V. L.; PEDRON, C. D. Programas de fidelidade: um estudo de múltiplos casos em empresas portuguesas. Brazilian Journal of Marketing - BJM Revista Brasileira de Marketing - ReMark. V., 13, n., 1, p. 60-74, jan./mar. 2014

MCKENNA, R. Marketing de Relacionamento: estratégias bem-sucedidas para a era do cliente. ed. 6 . Rio de Janeiro: Campus, 1997.

MCKENNA, R. Acesso total: o novo conceito de marketing de atendimento. Rio de Janeiro: Campus, 2002.

MELO, F. A. F.; FREITAS, A. A. F.; MELO, C. F. Customer Relationship Management (CRM) e a iniciação, preservação e finalização de relacionamentos: um estudo de caso múltiplo em pequenas empresas de tecnologia da informação. Revista da Micro e Pequena Empresa, Campo Limpo Paulista, v.3, n.2, p.106131, 2009. 
MORGAN, R. M.; HUNT, S. D. The commitment-trust theory of relationship marketing. Journal of Marketing, [S. I.], n. 58, p. 20-38, July 1994.

PARVATIYAR, A.; SHELTH, J. N. Customer relationship management: emerging practice, process, and discipline. Journal of Economic and Social Research, v.3, n.2, p.1-34, 2001.

PAYNE, A. Handbook of CRM: achieving excellence in customer management. Oxford: Elsevier, 2006.

PEPPERS E ROGERS GROUP. Estudo Brasil: fidelidade com resultados. HSM Management, p. 47-56, jul./ago. 2004.

REBOUÇAS, S. P. Metodologias de classificação supervisionada para análise de dados de microarrays. Trabalho acadêmico (Doutorado em Estatística e Investigação Operacional). Lisboa: Faculdade de Ciências da Universidade de Lisboa, 2011.

RIEGEL, V.; PEREIRA, M. L. A. Pão de Açúcar mais: o desafio do relacionamento. ESPM - Central de Cases, 2010. Disponível em: <http://www2.espm.br/ sites/default/files/pao_de_acucar_mais_0.pdf >. Acesso em: 18 out. 2017.

RODRIGUES, A. P. O Neovarejo: Um estudo de caso da loja conceito do Grupo Pão de Açúcar. Revista Diálogos Interdisciplinares, vol. 3, $n^{\circ} .2,2014$.

SANTOS, J. P.; SANTOS, H. O.; BEZERRA, V. H. B; MOREIRA, V. F; AZEVEDO, I. A. Análise das estratégias de Marketing de Relacionamento: Um estudo de caso em um mercadinho de bairro. Universidade Federal de Campina Grande - UFCG. AEDB, 2007.

SANTOS, C. M. C. Promessa de marca e a construção do marketing de valores: o caso do supermercado Pão de Açúcar. Monografia de conclusão de graduação para obtenção do grau de bacharel no curso de Comunicação Social com habilitação em Publicidade e Propaganda pela Universidade de Brasília - UnB - Brasília, 2013.

SBVC - Sociedade Brasileira de Varejo e Consumo. Estudo: o papel do varejo na economia brasileira. SBVC, 2018. Disponível em: <http://sbvc.com.br/estudo-o-papel-do-varejo-na-economia-brasileiraatualizacao-2018/>. Acesso em: 16 nov. 2018.

SILVA, S. A. L.; SANT'ANA, N. L. S.; MENEZES, J. P. C. B.; PAULA, J. S.; CHAIN, C. P. Métodos e técnicas quantitativas em contabilidade e Finanças : Uma Análise Sob a Ótica Do Software R. Pensar Contábil, v. 19, n. 68, p. 37-46, 2017.

SILVEIRA, J. A. G.; LEPSCH, S. L. Alterações Recentes na Economia do Setor Supermercadista Brasileiro - RAUSP (Revista de Administração da USP) - vol. 32 - Número 2 - São Paulo: USP, Abr./Jun. 1997.

SOUSA, J. C.; SILVA, P. M. M.; PINTO, F. R.; NASCIMENTO, A. L.; RABELO, L. N. A influência das redes sociais nas decisões de compras. Revista Gestão em Análise, Fortaleza, v. 7, n. 1, p. 118-127, jan./jun. 2018.

STONE, M.; WOODCOCK, N.; MACHTYNGER, L. CRM: marketing de relacionamento com os clientes. São Paulo: Futura, 2001.

VAVRA, T. G. Marketing de relacionamento: after marketing - como manter a fidelidade de clientes através do marketing de relacionamento. São Paulo: Atlas, 1993.

VINEREAN, S.; OPREANA, A. Consumer Engagement in Online Settings: Conceptualization and Validation of Measurement Scales. Expert Journal of Marketing, v. 3, n. 2, p. 35-50. 2015

WANG, Y.; YANG, Y. The impact and interaction effect of HR and IT applications on the performance of Customer Relationship Management in the Banking Industry: An Empirical Study of Five Taiwanese Banks. Information Resources Management Journal, v.28, n. 3, 2015. 
YIN, R. K. Case study research: design and methods. London: Sage, 1986.

YIN, R.K. Estudo de caso: planejamento e métodos. 3. ed. Porto Alegre: Bookman, 2005. 